\title{
How are children and adolescents cleaning their orthodontic appliances? A cross-sectional study in private schools
}

\author{
Mabel Miluska Suca Salas', Rita Regina Souza Lamas ${ }^{1}$, Tatiana Pereira Cenci', Rafael Guerra Lund ${ }^{1}$ \\ ${ }^{1}$ Universidade Federal de Pelotas - UFPel, School of Dentistry, Department of Restorative Dentistry, Pelotas, RS, Brasil
}

Received for publication: February 11, 2014 Accepted: March 12, 2014

Correspondence to: Rafael Guerra Lund Faculdade de Odontologia da Universidade Federal de Pelotas Rua Gonçalves Chaves 457 CEP: 96015568 Pelotas, RS, Brazil Phone: +55 5332226690 E-mail: rafael.lund@gmail.com

\begin{abstract}
Aim: To determine the prevalence and the hygiene methods used by 6 -16-year-old private school children and adolescents to clean removable orthodontic appliances (ROA) in the city of Pelotas, RS, Brazil. Methods: A cross-sectional study was conducted in private schools located in the urban area after the school tutors signed an informed consent form. Questionnaires were applied to children using removable orthodontic appliances. Data regarding hygiene methods of orthodontic appliances were collected. Descriptive analysis was performed. Pearson's chi-square test and Linear Trend with a confidence level of $95 \%$ were used for analytical analysis. Results: Children using ROA in private schools were $7.6 \%$. The most frequent hygiene method used was mechanical cleansing with toothbrush and toothpaste (85.6\%). Daily cleansing was the frequency most reported by children (51.6\%). Conclusions: Use of ROA in students from private schools was low and the most used hygiene method was brushing with toothpaste.
\end{abstract}

Keywords: removable orthodontic appliances; hygiene; disinfection; child; adolescent.

\section{Introduction}

The demand ${ }^{1}$ and use $^{2}$ of orthodontic appliances have increased in recent years. Studies have demonstrated that $16-28 \%$ children use removable orthodontic appliances $(\mathrm{ROA})^{2-4}$. The main reported reasons are aesthetics ${ }^{5}$ and occlusal dysfunctions ${ }^{6}$. ROA are indicated in occlusal correction and for dental retention after fixed treatment.

Studies have reported the increase of microorganisms such as Streptoccoccus mutans $^{7}$, Candida albicans ${ }^{8}$, Actinomyces, among others - after the placement of ROA in children ${ }^{910}$. The use of ROA increases the risk of developing dental caries $^{7}$, gingivitis ${ }^{11}$ and halitosis ${ }^{8}$. Studies have demonstrated higher incidence of initial caries lesions - white spots - associated with orthodontic appliances in children ${ }^{12}$. The presence of caries or gingival problems could compromise oral health of children and interfere indirectly in the social interaction of children ${ }^{13}$.

Proper hygiene can control the presence of bacterial biofilms, preventing oral problems ${ }^{14}$. Studies have investigated several hygiene methods for acrylic appliances ${ }^{15-20}$, with contradictory results. Some investigations showed that the combination of mechanical and chemical methods may reduce significantly the amount of bacteria compared to other methods ${ }^{16-17}$. Other studies found a significant reduction of oral microbiota with mechanical cleaning alone ${ }^{16,21}$, chlorhexidine solution $^{22}$ or effervescent tablets ${ }^{23-24}$. However, it is not clear whether children are 
actually using the most efficient methods for cleaning of orthodontic appliances and reduction of bacterial load.

The aim of the study was to determine the most used hygiene methods to clean ROA by 6-16-years-old children and adolescents from private schools in the city of Pelotas, RS, Brazil.

\section{Material and methods}

The present investigation was an observational crosssectional study. The population was children and adolescents from primary and secondary private schools in the urban area of Pelotas, a city in southern Brazil. The number of private schools in the city was obtained by a list provided by the Education Department of Pelotas. Day care centers and special schools were excluded.

Prior to the beginning of the research, the study was approved by the institutional Ethics Committee (registration number 216/2011) of the Federal University of Pelotas. The tutors responsible for each school signed an informed consent form for participation of children in the study. Children formally enrolled in private schools of the city that were users of ROA and had ability to answer the questionnaires were included. The teachers applied questionnaires in the classrooms.

The collected data included the total number of children per class, age of each child, number of students using removable orthodontic appliances, cleaning methods and frequency of cleaning of the removable appliances. The statistical analysis was descriptive. Pearson's chi-square with linear trend was used between children with removable appliances and age. The confidence level was $95 \%$.

\section{Results}

All private schools of the city $(n=21)$ participated in this study. A total of 6,706 students were invited and enrolled as participants. The response rate was $100 \%$. At the time of the survey, out of the 6,706 students, 507 were using removable orthodontic appliances, which represent a prevalence of $7.6 \%$.

A significant trend toward older children using ROA compared with younger children was observed (Table 1). Most children (98.0\%) with ROA cleaned their own appliances. The most commonly used method was mechanical cleaning with toothbrush and regular toothpaste $(90.0 \%)$, followed by Corega Tabs $^{\circledR}$ effervescent tablets $(5.0 \%)$.
Children cleaned their appliances at least once a day $(52.0 \%)$. Twenty one percent of children cleaned twice a day, $15.0 \%$ 3 times a day and $12.0 \%$ rarely cleaned the orthodontic appliances.

\section{Discussion}

Children from private schools using ROA were $7.6 \%$. This result revealed a lower prevalence of ROA users than in a recent study performed in Germany ${ }^{4}$ (2012), in which $16 \%$ of children aged 11-14 years old used ROA. Chesnutt et al. ${ }^{2}$ (2006) reported a frequency of $28 \%$ and $18 \%$ in 12 and 15 years old children, respectively, in England. This difference can be explained by the fact that Germany ${ }^{4}$ and England ${ }^{2}$ include orthodontic treatment as part of their health insurances. This makes the percentage of children with orthodontic treatment higher than in other countries. For instance, Germany is the country with the highest frequency of ROA treatments in Europe 4 . In Brazil, some private and public insurances include dental orthodontic treatments in dental health polices, but in a limited way.

Our sample was composed of students from private schools. Other studies observed that children with higher socioeconomic level were more frequently users of orthodontic appliances than those with lower socioeconomic level ${ }^{2-3}$. In our study, $7.6 \%$ of children used ROA.

On the other hand, there is a significant trend toward older children using removable orthodontic appliances. A trend could be observed regarding fixed and removable appliances. Studies usually found that younger children used ROA more frequently than older children ${ }^{2,25}$ and an opposite situation could be observed when children used fixed appliances ${ }^{2-3,25}$. Younger children usually used interceptive orthodontics as retainers and space maintainers in high frequency $(93 \%)$, older children often used ROA as dental space retainers and braces ${ }^{3}$. This could explain our findings. Most of the older children used fixed appliances and at the time of evaluation were wearing a dental retainer after the fixed orthodontic treatment.

This study showed that most of the children clean their ROA using a common toothbrush and toothpaste. The findings of the present study regarding the cleaning method used by children are consistent with those reported by Eichenauer et al. ${ }^{26}$ (2011), who stated that dentists reported to frequently indicate brushing with toothpaste the removable orthodontic appliances, followed by effervescent tablets (Corega Tabs ${ }^{\circledR}$ ).

Studies have investigated the hygiene methods used by users of ROA or acrylic removable prosthetic appliances. These

Table 1. Frequency of orthodontic treatments with removable appliances in 6-16 years old children and adolescents from private schools in the city of Pelotas, Brazil, 2011.

\begin{tabular}{|c|c|c|c|c|c|c|c|c|c|c|c|c|c|}
\hline \multicolumn{14}{|c|}{ Age (years) } \\
\hline $\begin{array}{l}\text { Orthodontic } \\
\text { treatment }\end{array}$ & $\begin{array}{c}\text { Total } \\
\text { N (\%) }\end{array}$ & 6 & 7 & 8 & 9 & 10 & 11 & 12 & 13 & 14 & 15 & 16 & $p$ value* \\
\hline No & 6,199 & $703(11.3)$ & $624(10.1)$ & $573(9.2)$ & $605(9.8)$ & $565(9.1)$ & $630(10.2)$ & $522(8.4)$ & $482(7.8)$ & $486(7.8)$ & $494(8.0)$ & $515(8.3)$ & \\
\hline
\end{tabular}


studies found that acrylic appliance users also frequently clean their appliances with toothbrush and toothpaste ${ }^{17}$, toothbrush and water $^{21}$ or with effervescent tablets ${ }^{24}$.

The cleaning method using only mechanical removal, without any chemical disinfectant agent, was reported as insufficient to remove the biofilm from the acrylic and does not adequately decrease the bacterial load ${ }^{16,18,20}$. An adjuvant chemical cleaning is required ${ }^{16,18-20}$.

Proper hygiene can control the presence of bacterial biofilm on tooth surfaces ${ }^{7}$. Data on the most appropriate method for cleaning orthodontic appliances are scarce, and there is not a standardized indication regarding the most efficient and effective technique or material to be used ${ }^{19}$.

Oral hygiene instructions for oral care and cleaning of the ROA acrylic baseplate by orthodontic patients are important keys to the promotion of health. Healthy behaviors such as control of dental biofilm can prevent gingival inflammation ${ }^{27}$ and tooth caries ${ }^{7}$.

Some limitations must to be pointed out. This study had a crossover design, which is limited to the time when data were collected. Furthermore, a specific group of the population was investigated, private school children and adolescents, which probably showed a different prevalence of ROA in child population. Despite the limitations, our findings may contribute to the knowledge of the methods used by children to clean their ROA and may add to future strategies for preventing biofilm control in orthodontic patients.

In conclusion, the prevalence of ROA used by students of primary and secondary private schools in the city Pelotas was low. Most of the children brush their appliances with regular toothpaste.

\section{Acknowledgments}

The authors are grateful to the State Secretary of Education, the Municipal Secretary of Education and the Direction of Private Schools, which allowed the study to be performed.

\section{References}

1. Ucuncu N, Ertugay E. The use of the Index of Orthodontic Treatment need (IOTN) in a school population and referred population. J Orthod. 2001; 28: 45-52.

2. Chestnutt IG, Burden DJ, Steele JG, Pitts NB, Nuttall NM, Morris AJ. The orthodontic condition of children in the United Kingdom, 2003. Br Dent J. 2006; 200: 609-12.

3. Pietila T, Pietila I, Widstrom E, Varrela J, Alanen P. Extent and provision of orthodontic services for children and adolescents in Finland. Community Dent Oral Epidemiol. 1997; 25: 150-5.

4. Krey KF, Hirsch C. Frequency of orthodontic treatment in German children and adolescents: influence of age, gender, and socio-economic status. Eur J Orthod. 2012; 34: 152-7.

5. Hamdan AM, Singh V, Rock W. Perceptions of dental aesthetics of Class III and anterior open bite malocclusions: a comparison between 10- to 11year-old schoolchildren and orthodontists. Angle Orthod. 2012; 82: 202-8.

6. Feu D, Oliveira BH, Celeste RK, Miguel JA. Influence of orthodontic treatment on adolescents' self-perceptions of esthetics. Am J Orthod Dentofacial Orthop. 2012; 141: 743-50.
7. Batoni G, Pardini M, Giannotti A, Ota F, Giuca MR, Gabriele M, et al. Effect of removable orthodontic appliances on oral colonisation by mutans streptococci in children. Eur J Oral Sci. 2001; 109: 388-92.

8. Vento-Zahra E, De Wever B, Decelis S, Mallia K, Camilleri S. Randomized, double-blind, placebo-controlled trial to test the efficacy of nitradine tablets in maxillary removable orthodontic appliance patients. Quintessence Int. 2011; 42: 37-43.

9. Amitha $\mathrm{H}$, Munshi AK. Effect of chlorhexidine gluconate mouth wash on the plaque microflora in children using intra oral appliances. J Clin Pediatr Dent. 1995; 20: 23-9.

10. Sarlas $\mathrm{CH}$, Ore DE. Intraoral bacterial changes with various pedodonticorthodontic appliances. ASDC J Dent Child. 1971; 28: 385-6.

11. Suga SS, Guedes-Pinto AC, Simionato MR. In vitro evaluation of the influence of resin acrylic surface polishing for orthodontic appliances on adhesion and removal of Streptococcus mutans. Dental Press Ortod Ortop Facial. 2005; 10: 94-107.

12. Øgaard B. White spot lesions during orthodontic treatment: mechanisms and fluoride preventive aspects. Semin Orthod. 2008; 14,: 183-93.

13. Agou S, Locker D, Muirhead V, Tompson B, Streiner DL. Does psychological well-being influence oral-health-related quality of life reports in children receiving orthodontic treatment? Am J Orthod Dentofacial Orthop. 2011; 139: 369-77.

14. Souza RF, Regis RR, Nascimento C, Paranhos HF, Silva CH. Domestic use of a disclosing solution for denture hygiene: a randomised trial. Gerodontology. 2010; 27: 193-8.

15. da Silva FC, Kimpara ET, Mancini MN, Balducci I, Jorge AO, Koga-Ito CY. Effectiveness of six different disinfectants on removing five microbial species and effects on the topographic characteristics of acrylic resin. $J$ Prosthodont. 2008; 17: 627-33

16. Paranhos HF, Silva-Lovato CH, de Souza RF, de Freitas-Pontes KM, Watanabe $E$, Ito IY. Effect of three methods for cleaning dentures on biofilms formed in vitro on acrylic resin. J Prosthodont. 2009; 18: 427-31.

17. Mahonen K, Virtanen $\mathrm{K}$, Larmas $\mathrm{M}$. The effect of prosthesis disinfection on salivary microbial levels. J Oral Rehabil. 1998; 25: 304-10.

18. de Souza RF, de Freitas Oliveira Paranhos H, Lovato da Silva $\mathrm{CH}, \mathrm{Abu}$ Naba'a L, Fedorowicz Z, Gurgan CA. Interventions for cleaning dentures in adults. Cochrane Database Syst Rev. 2009; 7(4): CD007395.

19. Peixoto IT, Enoki C, Ito IY, Matsumoto MA, Nelson-Filho P. Evaluation of home disinfection protocols for acrylic baseplates of removable orthodontic appliances: A randomized clinical investigation. Am J Orthod Dentofacial Orthop. 2011; 140: 51-7.

20. Panzeri H, Lara EH, Paranhos H de F, Lovato da Silva $\mathrm{CH}$, de Souza $\mathrm{RF}$, de Souza Gugelmin MC, et al. In vitro and clinical evaluation of specific dentifrices for complete denture hygiene. Gerodontology. 2009; 26: 26-33.

21. Tarbet WJ, Axelrod S, Minkoff S, Fratarcangelo PA. Denture cleansing: a comparison of two methods. J Prosthet Dent. 1984; 51: 322-5.

22. Friedman M, Harari D, Raz H, Golomb G, Brayer L. Plaque inhibition by sustained release of chlorhexidine from removable appliances. J Dent Res. 1985; 64: 1319-21.

23. Nisayif $\mathrm{DH}$. The effects of removable orthodontic appliance hygiene on oral flora. J Bagh Col Dent. 2009; 21: 105-8.

24. Chan EC, lugovaz I, Siboo R, Bilyk M, Barolet R, Amsel R, et al. Comparison of two popular methods for removal and killing of bacteria from dentures. J Can DentAssoc. 1991; 57: 937-9.

25. Kavaliauskiene A, Sidlauskas A, Zaborskis A. Demographic and social inequalities in need for orthodontic treatment among schoolchildren in Lithuania. Medicina (Kaunas). 2010; 46: 767-73.

26. Eichenauer J, Serbesis C, Ruf S. Cleaning removable orthodontic appliances: a survey. J Orofac Orthop. 2011; 72: 389-95.

27. Dersot JM. [Plaque control, a key element of successful orthodontics]. Orthod Fr. 2010; 81: 33-9. 